\title{
Research Paper \\ Determining the Relationship Between Landscape Structure and Mental Components on Thermal Assessment
}

\author{
Katayoun Afshon $^{1}$ (D), Mohsen Taban ${ }^{2,3}$ (D), Mostaf Masoudinejad ${ }^{1 *}$ iD, Reza Jalilzadeh Yengejeh ${ }^{4}$ (iD \\ 1. Department of Architecture, Ahvaz Branch, Islamic Azad University, Ahvaz, Iran. \\ 2. Department of Architecture, Visiting Professor, Ahvaz Branch, Islamic Azad University, Ahvaz, Iran. \\ 3. Jundishapur University of Technology, Dezful, Iran. \\ 4. Department of Environmental Engineering, Jundishapur University of Technology, Dezful, Iran.
}

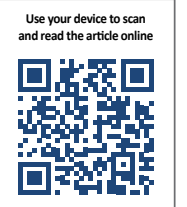

Citat on Afshon K, Taban M, Masoudinejad M, Jalilzadeh Yengejeh R. Determining the Relationship Between Landscape Structure and Mental Components on Thermal Assessment. J Adv Environ Health Res. 2021; 9(3):255-264. http://dx.doi. org/10.32598/JAEHR.9.3.1225

doi http://dx.doi.org/10.32598/JAEHR.9.3.1225

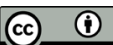

Article info:

Received: 19 Apr 2020

Accepted: 17 Jun 2020

Publish: 01 Jul 2021

\section{Keywords:}

Urban open spaces, Mental components, Landscape structure, Thermal assessment, Karoon River

\section{A B STRACT}

Background: The urban open spaces and their effects on the physical and mental health highlights the attention on the quality of such spaces. Thermal comfort is an environmental component affecting the reactionary behavior of people in these spaces. The present study aimed to investigate the relationship between mental components and landscape structure and its effects on the thermal assessment of individuals.

Methods: In this study, we used the descriptive method for explaining the mental components and landscape structure. Then, the survey method was employed for determining the correlations between research variables. Finally, we used the experimental method for testing the variables using specific tools. Thermal analysis was done by computer simulation method using ENVI-met software in the Karoon river area in Ahvaz City, Iran. UTCI (universal thermal climate index) is the index used for assessing thermal comfort. To find out the relationship between the research variables, the field data were randomly collected by questionnaires using the Cochran formula.

Results: The findings demonstrated the existence of a relationship between landscape structure and different mental states in individuals. The moods of the individuals in open spaces affect their perceptions of the landscape and thermal assessment of the environment.

Conclusions: Eventually, and based on the study findings, it was found that people's mental states in different situations affect their perception of the landscape's quality and structure and reactionary behavior. It also influences their thermal assessment.

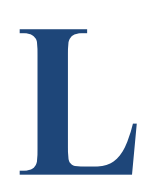

\section{Introduction}

andscape is a type of space that results from the interaction between humans and the outside environment [1]. It has the nature of the place but is the product of human experience in a space [2]. Tom Turner calls the city a landscape and believes that the most fundamental basis of a city is what we perceive

* Corresponding Author:

Mostaf Masoudinejad, PhD.

Address: Department of Architecture, Ahvaz Branch, Islamic Azad University, Ahvaz, Iran.

Phone: +98 (912) 8142307

E-mail: mostafa_masoudinejad@yahoo.com 
[3]. City landscape is the interface between man and the urban phenomenon [4]. Some experts call it an objective reality; some consider it a subjective reality, definable in the mind of citizens. Still, most believe that objective and subjective aspects both comprise the predominant feature of the urban landscape. They argue that objective and subjective aspects are interdependent and necessary to define urban landscape [5]. Creating comfort in these urban landscapes is directly related to how much people use them and people's type of behavior and kind of presence [6]. Meanwhile, it is crucial to consider the general comfort resulting from climate, called thermal comfort [7].

To evaluate the thermal comfort in the urban landscape, it is not enough to use a quantitative approach to describe the conditions, but we need to consider mental adaptation and parameters [8]. Because the features and structure of these spaces affect human mental health and produce different reactionary behaviors [9]. In this regard, Rabiatul et al. have emphasized the necessity of mechanisms of perception and adaptation to thermal comfort in open spaces. These mechanisms show the thermal adaptation of responders from the physiological point of view. Also, they believed in the crucial effects of micrometric parameters and individual characteristics in people's perception of the urban open spaces [10].

People from various cultures and characteristics express different behavior in similar conditions [11]. In such a situation, the environment is critical for controlling reactionary behavior. By recognizing the undesirable factors in architectural spaces, the negative reactionary behavior could be modified $[12,13]$. In fact, it could be said that physical criteria and landscape structure have significant impacts on thermal comfort of urban open spaces and micro-climates - from texture to structure, including physical elements like height, confinement, vegetation, etc. - and must be taken into account $[13,14]$.

However, despite the significant number of studies regarding urban outdoor spaces design and its importance for using these places, studies in this area are still few compared with studies on climate comfort in indoor spaces [14]. Consequently, lack of scientific resources for this topic has led to inefficient designs in urban open spaces and undesirable effects on human health, comfort condition, and even social condition [15].

Hence, considering the lack of literature in the climatic design of the urban open spaces and its proven effects, it is necessary to compile efficient designing methods to upgrade thermal comfort quality in urban open spaces. It seems that there is a relationship between the landscape structure, mental components, and thermal assessment of individuals. Then, based on the research hypothesis, this question is raised about how the relationships are between the landscape structure of Karoon river bank, the mental feeling of individuals, and their effect on the way individuals assess the temperature.

The present study aims to assess the mental components of the users in the urban river landscapes and their effects on the thermal response of the users. First, we investigated the thermal comfort of the area and then assessed the impact of desirable or undesirable thermal comfort conditions and mental components and psychological responses on each other. Besides, after evaluating the mentioned factors, we address the relationship between thermal comfort changes and landscape figure and their effects on each other.

\section{Materials and Methods}

\section{Research method}

This research is an applied study in terms of its objectives. The research design is a mixed-method, including a descriptive method for explaining mental and thermal comfort components, a survey method for determining the correlation between research variables, and an experimental method for testing variables with climate simulating software. Based on the research findings, a questionnaire for assessing mental components and landscape structure was prepared. Also, another questionnaire based on a 7-point scale of Ashrae [16] was used for analyzing the thermal sensation of individuals. The parameters affecting the thermal comfort, including temperature, humidity, globe temperature, wind speed, etc., were measured by ENVI-met software in the study area. The questionnaires were distributed in the statistical sample $(n=384)$ calculated by the Cochran formula considering $2 \%$ error.

\section{Study area in terms of time and place}

Considering the significant role of the rivers as the main artery of Ahvaz urban structure, which is located in a warm and semi-humid climate and has an acute climatic condition, we chose the urban bank of the Karoon river for the research to test the obtained criteria. Based on the features and structure of the landscape, a part of the riverbank was chosen, and the data analysis was done on the east side of the river. By considering the physical, identity, and aesthetic characteristics (land appearance) of the landscape, four sites or stations were chosen for data collection and processing. The climatic data were taken dur- 
ing a 24-hour period on June 22. Then, the modeling of the area was presented with temperature charts, humidity, wind, mean radiant temperature at $9 \mathrm{AM}$ and $5 \mathrm{PM}$.

\section{Results and Discussion}

Examining the landscape structure in selected stations

To compare accurately the sites selected from the environment, it is crucial to analyze and survey the stations (Table 1). As stated before, four sites were chosen as data collection stations at the eastern side of the river that provided the climatic parameter data in 24 hours. Of these stations, two were near the vegetation area with trees, and the other two were at open areas and squares containing multiple pavement materials (Figure 1).

\section{Examining the mental components}

To determine the dimensions of mental components, we reviewed the relevant studies and interviewed experts in the psychological field. In the end, four reactionary behaviors were chosen based on which a proper questionnaire was prepared. The validity of the questionnaire was approved, by five experts, before its distribution. The selected reactionary behaviors are shown in Figure 2. Also, for determining the mental state of individuals at the time of data collection, some questions were asked, and according to the conducted surveys, it was found that the individuals' responses in different mental states could be combinational and tend toward one side of the spectrum that change their thermal responses.

\section{Checking the comfort condition of the area}

Analyzing the data processors located at the environment

To analyze the individuals' thermal assessments, it is necessary to study the thermal comfort state in the area. This condition was investigated on June 22, the beginning

of summer in Iran. At this stage, the data were fed into the software, and the period of model analysis and climatic data were based on the 50-year climatic data of Ahvaz Energy plus (energyplus.com). The data were studied with Weather Tool software. Then, the hourly output was taken and entered the ENVI-met for June 22. The climatic data that were put into ENVI-met included the temperature (on Kelvin temperature scale), direction and speed of the wind measured in $10 \mathrm{~m}$ above the ground, relative humidity, and specific humidity. Figure 3 shows the processing operation and input data given to ENVI-met.

\section{Initial modeling by ENVI-met}

By using ENVI-met, the positions of all items at the site, such as vegetation, water zone, building masses, different material at the site, etc., were specified. Since the stations were at the east side of the river, this modeling was for the eastern area of the river (Figure 4).

\section{Charts for the current condition of the area under analysis}

The output graphs display the state of the climatic components on the east side of the river, including temperature, humidity, wind, and the mean radiant temperature, which affect thermal comfort from 9 AM till 5 PM.

\section{Temperature}

Figures 5 and 6 show that at 9 AM, the minimum temperature is $31.2^{\circ} \mathrm{C}$, and the maximum is $35.77^{\circ} \mathrm{C}$. According to the graphs, the increase in temperature at the street in the early morning could be due to the radiant by the asphalt of the street surface. In the graph, the temperature at $5 \mathrm{PM}$ increased due to the constant solar radiation over the area under study, which led to a higher increase in temperature in the center of the site and building exterior views.

\section{Relative humidity}

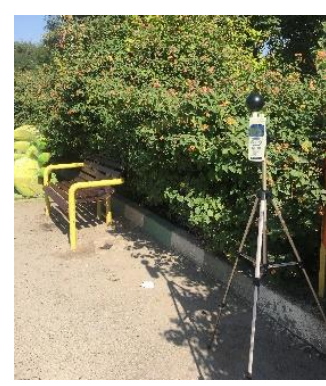

Station 3

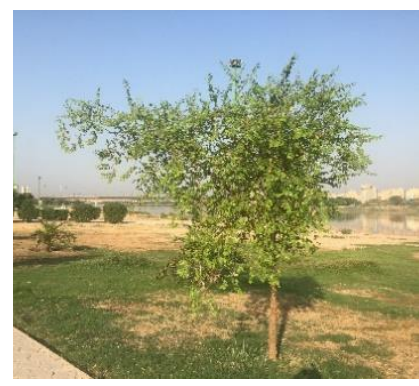

Station 4

Figure 1. Pictures of selected stations for the project 
Table 1. Features and landscape structure in selected stations

\begin{tabular}{|c|c|c|c|c|c|c|c|c|c|c|}
\hline \multirow[b]{2}{*}{ Stations } & \multirow[b]{2}{*}{$\begin{array}{l}\text { Crowd- } \\
\text { ing }\end{array}$} & \multirow{2}{*}{$\begin{array}{c}\text { Sky View } \\
\text { Factor } \\
\text { (SVF) }\end{array}$} & \multicolumn{3}{|c|}{ Physical Features } & \multicolumn{2}{|c|}{ Identity Features } & \multicolumn{3}{|c|}{$\begin{array}{l}\text { Aesthetic Features (Land Ap- } \\
\text { pearance) }\end{array}$} \\
\hline & & & Vegetation & $\begin{array}{l}\text { Micro- } \\
\text { space }\end{array}$ & $\begin{array}{c}\text { Urban } \\
\text { Furniture }\end{array}$ & $\begin{array}{l}\text { Sign and } \\
\text { Symbol }\end{array}$ & $\begin{array}{l}\text { Tomb or } \\
\text { Memorial } \\
\text { Building }\end{array}$ & Lighting & $\begin{array}{l}\text { Pave- } \\
\text { ment }\end{array}$ & $\begin{array}{l}\text { Topogra- } \\
\text { phy }\end{array}$ \\
\hline 1 & Crowded & 0.35 & Dense & $\begin{array}{l}\text { Lale } \\
\text { Park }\end{array}$ & Yes & Yes & No & Yes & Grass & Yes \\
\hline 2 & Crowded & 1 & $\begin{array}{l}\text { Dense with } \\
\text { pattern }\end{array}$ & $\begin{array}{l}\text { Lale } \\
\text { Park }\end{array}$ & Yes & Yes & No & Yes & Mosaic & Yes \\
\hline 3 & Crowded & 0.91 & Thin & $\begin{array}{l}\text { Play- } \\
\text { ground }\end{array}$ & Yes & Yes & No & Yes & Asphalt & No \\
\hline 4 & $\begin{array}{l}\text { Not } \\
\text { crowded }\end{array}$ & 1 & Dense & Park & No & No & No & No & Mosaic & No \\
\hline
\end{tabular}

Regarding the relative humidity graphs taken at 9 AM and 5 PM, in the early morning, there is a considerable amount of humidity in the airflow because of the short time of sun being exposed to the area and the air flowing among the trees and building environments has caused fluctuations in the amount of humidity. In areas with dense vegetation and short trees or the areas nearer to the masses of taller buildings, the relative humidity decreased at $5 \mathrm{PM}$ after several hours of direct sunlight to the site and warming up the environment (Figures 7 and 8).

\section{Wind speed}

The wind speed in this area at both 9 AM and 5 PM was approximately similar in most parts of the sites because of the absence of tall buildings and the presence of thin vegetation with a scattered pattern of planting. The fastest wind speed in this complex is $1.8 \mathrm{~m} / \mathrm{s}$. Also, among the buildings and near the dense vegetation, a decrease in wind speed is witnessed. In other areas, the wind speed is relatively similar because of the absence of significant and notable barriers (Figures 9 and 10). Several studies have been conducted on the effect of wind flow on urban open spaces, which report the impact of ventilation on temperature changes and thermal comfort [17].

\section{Radiant temperature}

Recently, the effect of landscape structure of urban spaces on solar radiation and its impact on pedestrian thermal comfort has been studied [18]. In this area, except for places near the buildings and vegetation which created shadows, the mean radiant temperature at 9 AM is in the same range. This parameter has a higher mean radiant temperature at $5 \mathrm{PM}$ due to the constant shining of the sun on the surfaces and crusts throughout the day. Moreover, this parameter increases the surface temperature of materials (Figures 11 and 12).

\section{Calculating UTCI and examining the comfort con- dition of the area}

At this stage, based on the outputs taken from ENVImet, which include wind speed, temperature, relative humidity, and mean radiant temperature, and by using Relation 1, the minimum, maximum, and mean values of UTCI (universal thermal climate index) were extracted

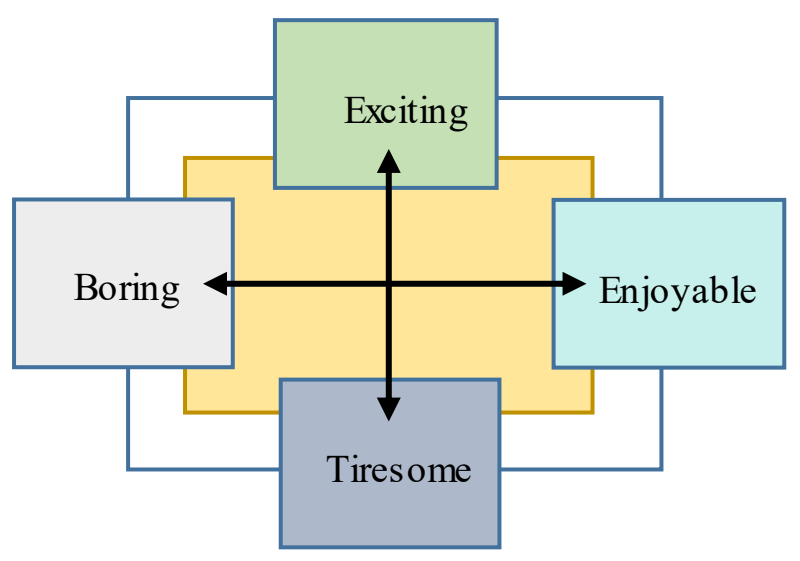

Figure 2. Selected reactionary behavior 


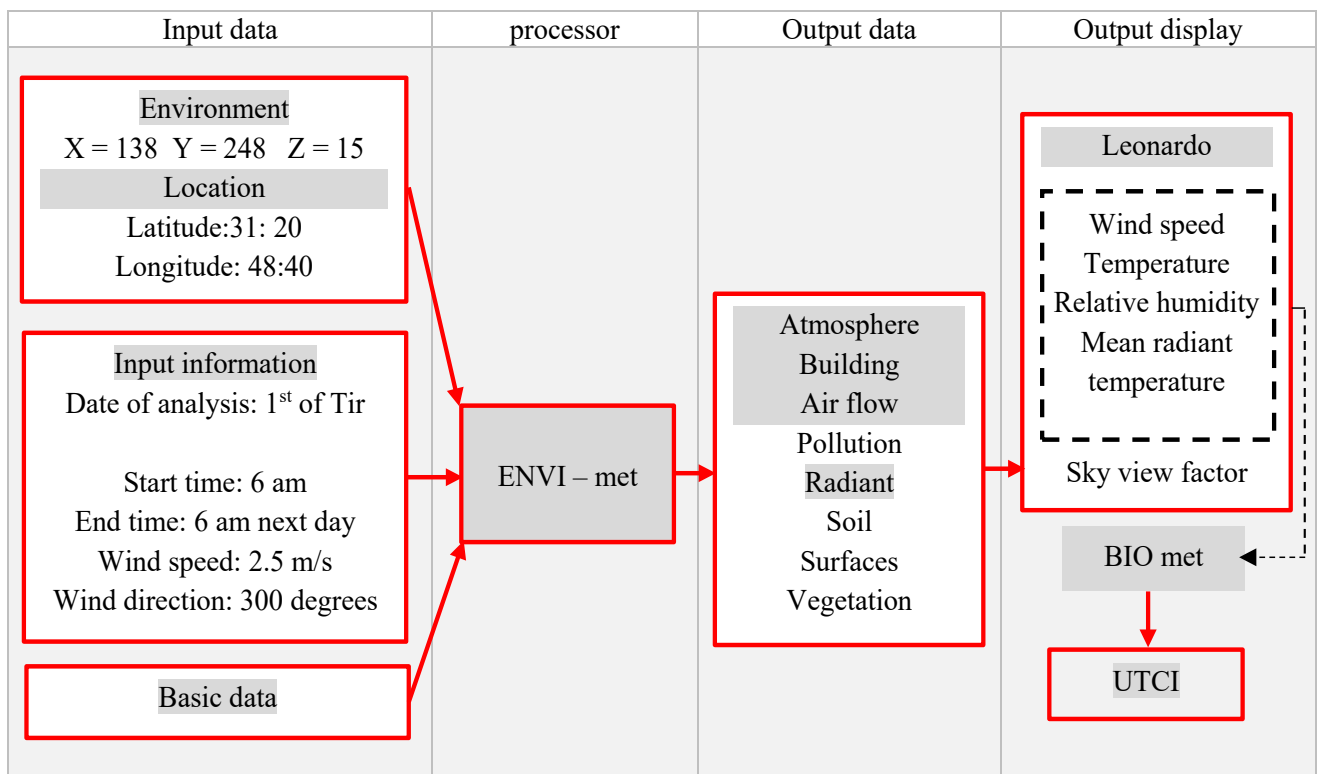

Figure 3. Procedure method and input data

for each station. According to the heat stress thresholds of UTCI [19], there is heat stress in terms of comfort conditions in all stations (Table 2). So that the minimum and mean amount of this indicator were on the moderate to high heat stress state and the maximum amount was at the high heat stress state (Equation 1).

(1) $U T C I=3.21+0.872 T+0.2459 T m r t+(-2.5078 . V)$ 0.0176.RH

In Relation 1, T stands for temperature in ${ }^{\circ} \mathrm{C}$, Tmrt denotes mean radiant temperature in ${ }^{\circ} \mathrm{C}, \mathrm{V}$ stands for wind speed in $\mathrm{m} / \mathrm{s}$, and RH represents the humidity rate in percentage. One important input for calculating UTCI is the mean radiant temperature (Tmrt). This input expresses the thermal effect of the sunshine and temperature on humans and shows an uneven surface in an imaginary area surrounding a person [20]. It is calculated by ENVI-met.

\section{Analysis of questionnaires' data}

A qualitative study of mental components and landscape structure data extracted from the questionnaires distributed among the people present at the sites was done in the test times. The questionnaires were compiled and distributed according to the Ashrae 7-point scale. Afterward, SPSS v. 22 was used to analyze the obtained data from the questionnaires and find the relationship between the mentioned components.

The research hypothesis states that there are relationships between landscape structure, mental components, and thermal assessment of the individuals. In this study, the dispersal chart proves the existence of relationships between landscape structure, and mental components, too. For determining this relationship and its strength, a statistical test was performed (Figure 13).

According to Table 3, the resulting value is less than 0.05 , and the relationship between the variables is con-

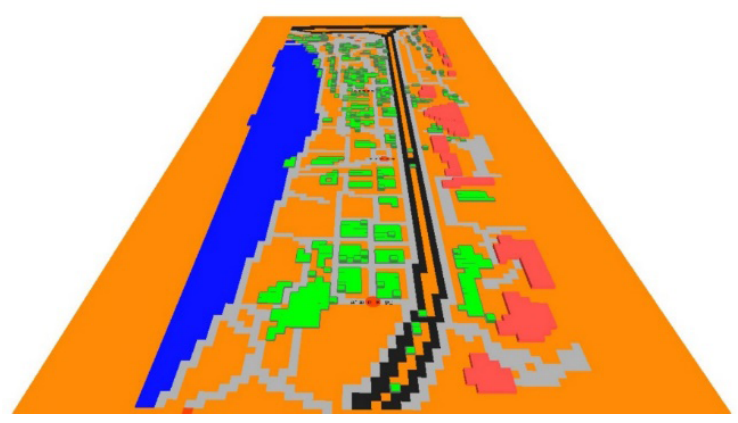

Figure 4. Initial models of the east side of the river 


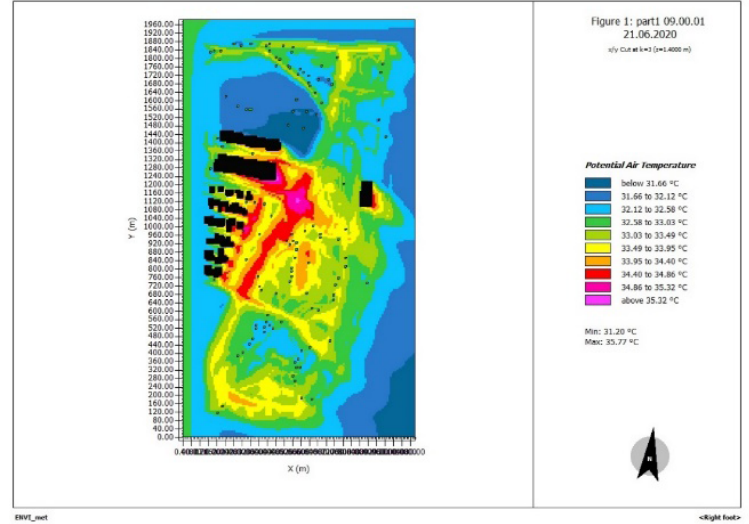

Figure 5. Temperature graph of $9 \mathrm{AM}$

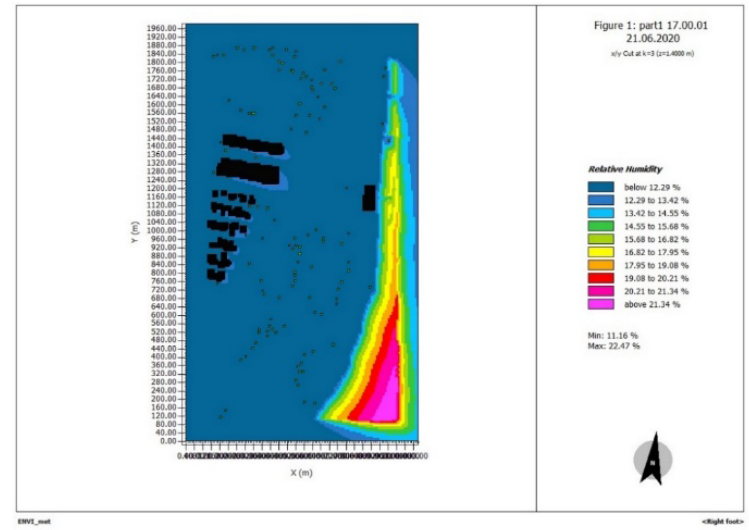

Figure 7. Humidity at $9 \mathrm{AM}$

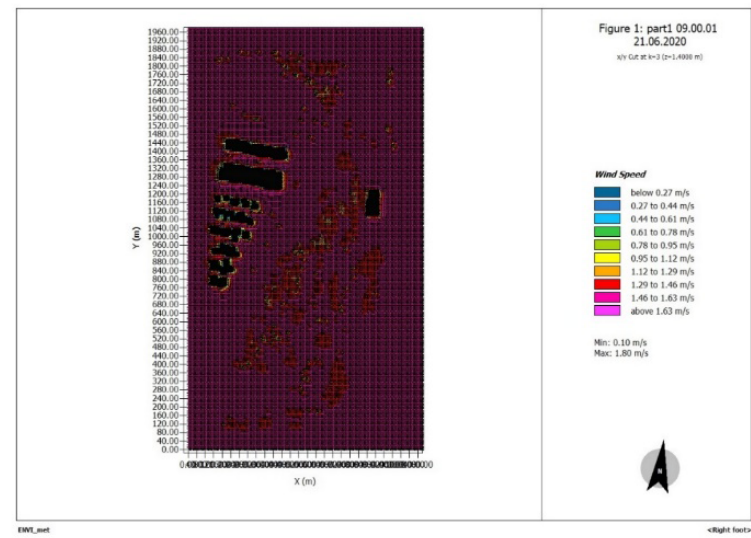

Figure 9. Wind speed at $9 \mathrm{AM}$

firmed. The coefficient of this correlation is 0.665 . This figure suggests that landscape structure affects the mental assessment of the individuals, and its effect is significant. The inspiration that riverbank creates in people could give them a feeling of comfort.

Recent studies have examined the average thermal comfort in hot and humid climates and the relationship between thermal comfort and users' feelings in open

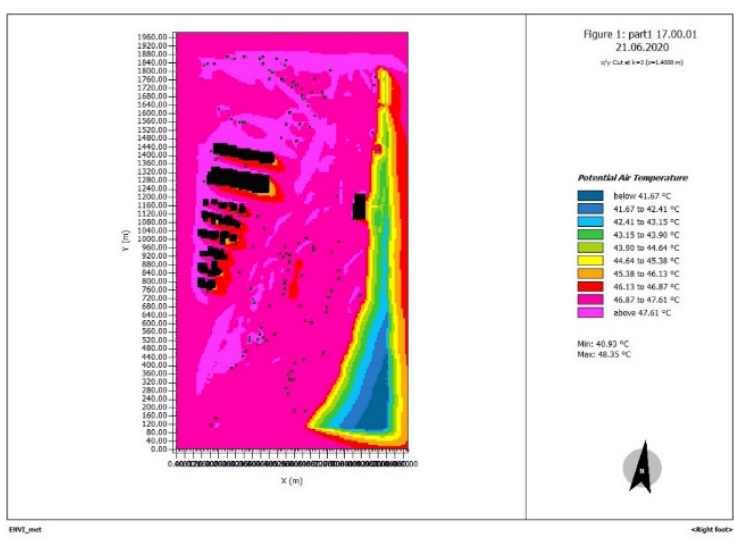

Figure 6. Temperature graph of 5 PM

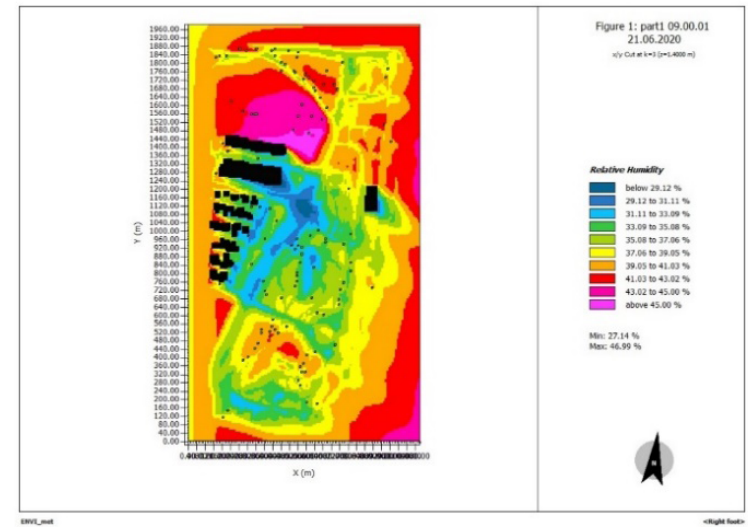

Figure 8. Humidity at $5 \mathrm{PM}$

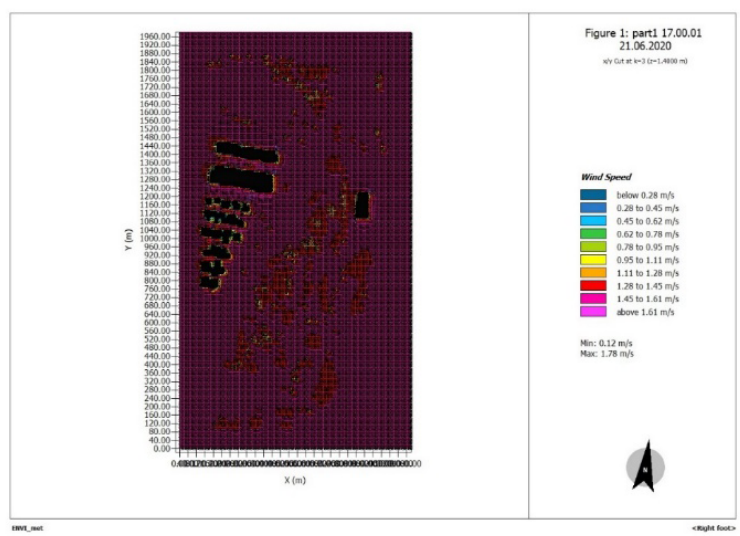

Figure 10. Wind speed at $5 \mathrm{AM}$

environments. However, these studies overlooked the role and effect of landscape structure on thermal comfort and mental components and the interactions of these three components [21]. In this research, based on data, in station 1, the UTCI value of 31.5 showed medium heat stress in the area. According to the studies done, the positive mental and spiritual state of the individuals and the feeling of belonging to the environment has changed their thermal response and expressed it as neutral. In 


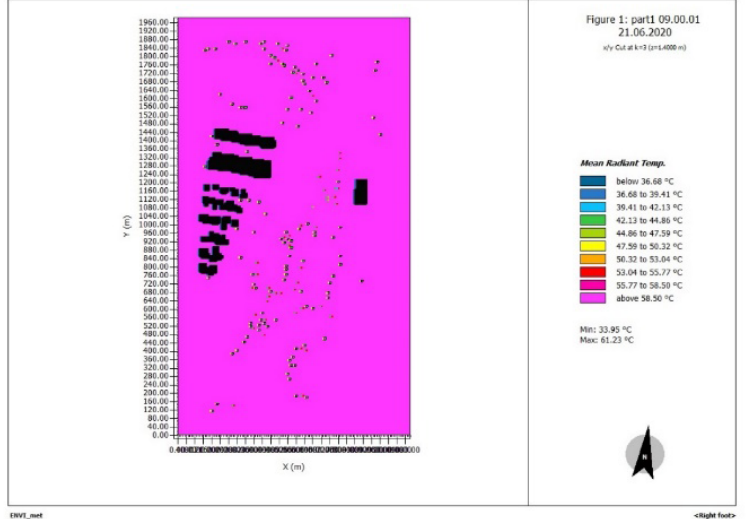

Figure 11. Radiant temperature at $9 \mathrm{AM}$

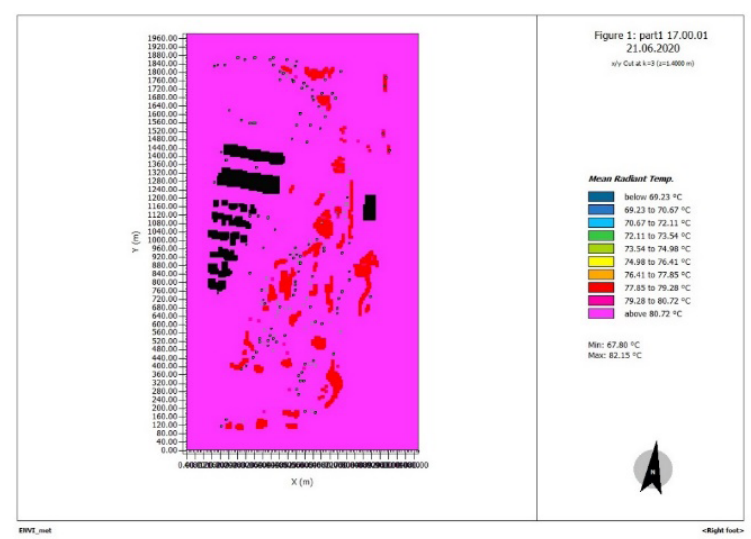

Figure 12. Radiant temperature at 5 PM

Table 2. UTCI amount in four selected stations

\begin{tabular}{|c|c|c|c|c|c|c|}
\hline \multirow{2}{*}{ Stations } & \multicolumn{3}{|c|}{ Comfort State } & \multicolumn{3}{|c|}{ Universal Thermal Climate Index } \\
\hline & Min. & Max. & Mean & Min. & Max. & Mean \\
\hline 1 & $\begin{array}{l}\text { Moderate heat } \\
\text { stress }\end{array}$ & High heat stress & High heat stress & 31.5 & 60.93 & 46.21 \\
\hline 2 & $\begin{array}{l}\text { Moderate heat } \\
\text { stress }\end{array}$ & High heat stress & $\begin{array}{l}\text { Extreme heat } \\
\text { stress }\end{array}$ & 30.37 & 61.02 & 45.69 \\
\hline 3 & High heat stress & High heat stress & High heat stress & 32.08 & 61.05 & 46.56 \\
\hline 4 & $\begin{array}{l}\text { Moderate heat } \\
\text { stress }\end{array}$ & High heat stress & $\begin{array}{l}\text { Extreme heat } \\
\text { stress }\end{array}$ & 30.63 & 60.58 & 45.6 \\
\hline
\end{tabular}

contrast, they have described the landscape quality and structure as positive. Station 4 has had an opposite condition to station 1. Although the situation, in terms of comfort, is like station 1 with medium heat stress, the thermal assessment and landscape quality have been interpreted as negative due to the individual's spiritual and mental unfavorable state. Thus, the person had either been in an unfavorable spiritual state before arriving at the area or after staying at the site, he was affected by the unfavorable quality of the landscape, and his mood had changed. Accordingly, in both conditions, there is a significant relationship between the mental state and an individual's thermal assessment. In other words, the people's spiritual and mental state could affect their eval-

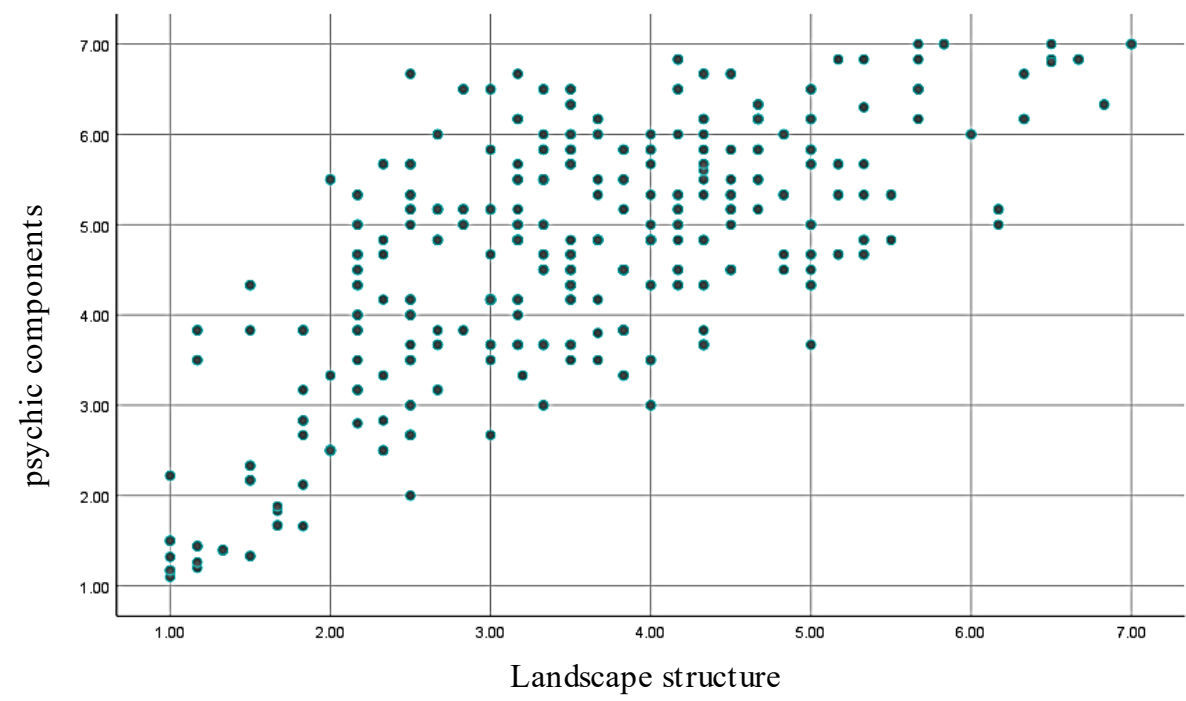

Figure 13. The dispersal chart of landscape structure and mental components 
Table 3. The significance level of landscape structure and mental components

\begin{tabular}{ccc}
\hline Model & Correlation Coefficient & Significance Level \\
\hline Landscape structure mental components & 0.665 & 0.0001 \\
\hline
\end{tabular}

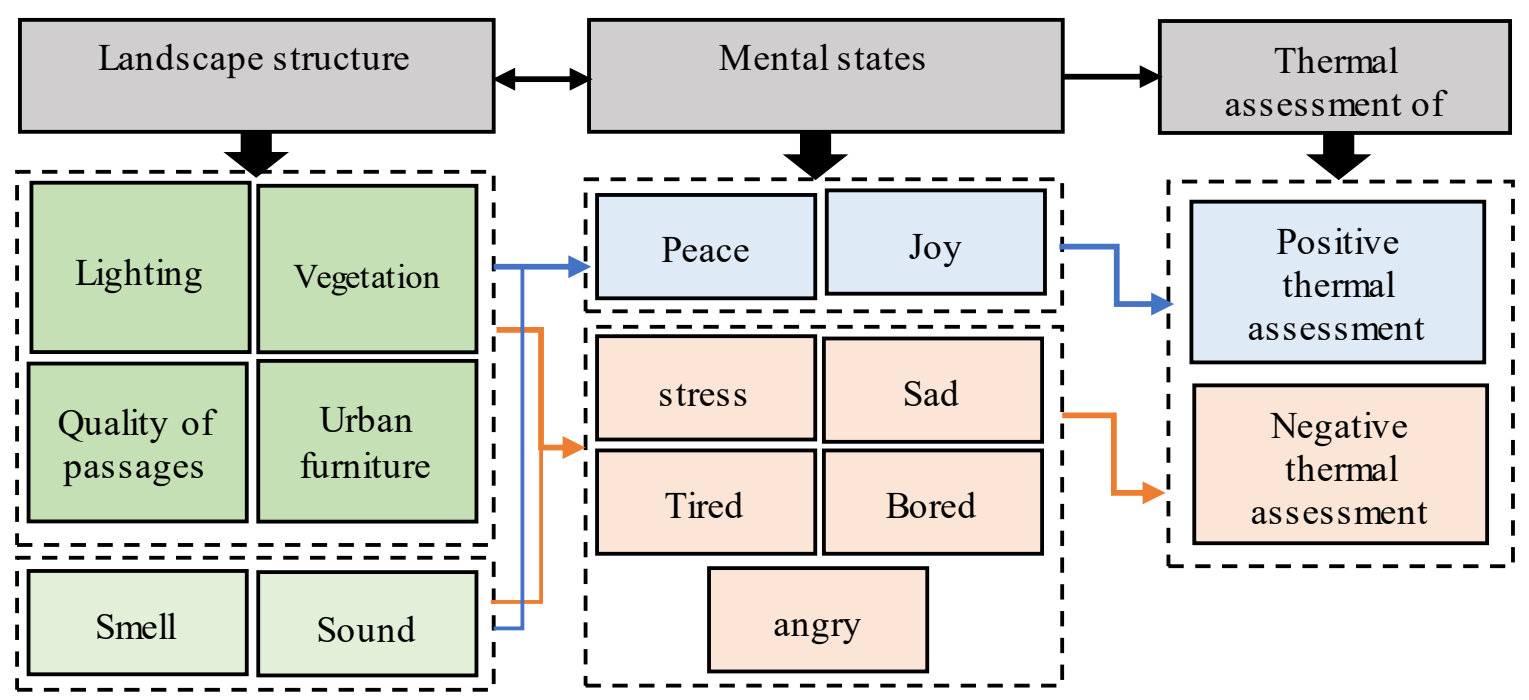

Figure 14. The relationship between landscape structure and the mental states

uation of heat, landscape quality, and structure and lead to unexpected and different responses.

\section{Conclusion}

According to the data extracted from the questionnaires and their analysis and based on the comfort condition and mental state of individuals and environmental condition, the relationship between mental components and landscape structure is confirmed with a correlation coefficient of 0.665 . This relationship is also bilateral. On the one hand, the mental state of the individuals could affect their response to the environment and landscape quality and features (in terms of vegetation, lighting, smells and sounds in the area, urban furniture, equipment, and passages quality), and on the other hand, landscape quality could affect the mental state of individuals and change their feeling of being in an open area near the river.

Also, the mental components of individuals could affect their thermal assessment and create different and unexpected responses to the comfort condition of the environment. For instance, individuals in stations with favorable landscape conditions, in terms of vegetation, connection to the river, etc., but with negative mental state, described the landscape as boring and tiresome, and their thermal assessment was also negative in this condition. On the contrary, individuals in stations with low-quality landscapes, especially in terms of vegetation, urban furniture, urban equipment, and quality of passages, even in the absence of comfort conditions, had positive thermal responses and described the landscape as exciting and enjoyable. This finding proves the relationship between the effect of mental components on the analysis and description of the landscape and the thermal assessment of individuals of the environment (Figure 14).

\section{Ethical Considerations}

\section{Compliance with ethical guidelines}

This study was approved by the Islamic Azad University, Ahvaz Branch, Iran (Code: 106482002285519162249730). Also, the participants were informed of the purpose of the research and its implementation stages. Written consent has been obtained from the subjects. They were also assured about the confidentiality of their information and were free to leave the study whenever they wished, and if desired, the research results would be available to them. The Helsinki Convention was also observed.

\section{Funding}

The paper was extracted from a $\mathrm{PhD}$. dissertation of the first author at the Department of Architecture, Faculty of Basic Sciences, Islamic Azad University, Ahvaz Branch. 


\section{Authors' contributions}

Conceptualization and study design, literature review, preparing the questionnaire, data analysis and interpretation, manuscript preparation, and editing: Katayoun Afshoun; Study design, questionnaire preparation, and data input: Mohsen Taban; Methodology, writing, review and editing, and project administration: Mostafa Masoudinejad; Methodology, review and editing, and investigation: Reza Jalilzadeh Yengejeh.

\section{Conflict of interest}

The authors declared no conflict of interest.

\section{Acknowledgments}

The authors would like to express their sincere gratitude to the authorities of Ahvaz Islamic Azad University of Ahvaz Branch, Iran, and the Architecture Department and Department of Environmental Engineering.

\section{References}

[1] Taghvae SH. Landscape architecture: In introduction to definitions and theoretical foundations. Tehran: Shahid Beheshti University; 2012. https://www.researchgate.net/publication/335777742_Landscape_Architecture_an_Introduction_ to_Concepts_Theories

[2] Jalilzadeh Yengejeh R, Morshedi J, Yazdizadeh R. The study and zoning of Dissolved Oxygen (DO) and Biochemical Oxygen Demand (BOD) of Dez river by GIS software. J Appl Res Water Wastewater. 2014; 1(1):23-7. https://arww.razi.ac.ir/ article_47.html

[3] Mahan A, Mansoori SA. The concept of landscape with emphasis on the opinion of experts in various fields. Journal of Bagh-e Nazar. 2017; 14(47):17-25. http://www.bagh-sj.com/ article_45081.html?lang=en

[4] Faizi M. [Urban landscape: A comparative study of three concepts in the city (Persain)]. Manzar Shahri. 2010; 9. http:// ensani.ir/fa/article $\% \mathrm{~B} 1$

[5] Mansoori T, Jahanbakhsh H. [Exploring how to improve the urban landscape through the body and revive cultural valuesHistoric City (Persian)]. Q J Phys Dev Plann. 2013; 1(3):89-102. http://psp.journals.pnu.ac.ir/article_2172.html?lang=fa

[6] Berry LM, May J, Andrade J, Kavanagh D. Emotional and behavioral reaction to intrusive thoughts. Assessment. 2010; 17(1):126-37. [DOI:10.1177/1073191109344694] [PMID]

[7] Zabetiyan E, kheirodin R. [Assessment hierarchy model of the relationship between psychological adaptation for achieving thermal comfort and sense of place in urban spaces (Per- sian)]. Motaleate Shahri. 2018; 7(28):79-90. https://urbstudies.uok.ac.ir/article_60899.html?lang=en

[8] Heydari SH, Monam A. [Evaluation of thermal comfort indices in outdoor space (Persian)]. Geogr Reg Dev. 2013; 11(1):197-216. [DOI:10.22067/GEOGRAPHY.V11I20.30753]

[9] Parsons K. Human thermal environments: The effects of hot, moderate, and cold environments on human health, comfort, and performance. Boca Raton: CRC Press; 2014. [DOI:10.1201/b16750]

[10] Rabiatul AN, Sabarinah Sh A, Azni ZN. Psychological adaptation of outdoor thermal comfort in shaded green spaces in Malaysia. Procedia Soc Behav Sci. 2012; 68:865-78. [DOI:10.1016/j.sbspro.2012.12.273]

[11] Steiner F. Landscape ecological urbanism: Origins and trajectories. Landsc Urban Plan. 2011; 100(4):333-7. [DOI:10.1016/j.landurbplan.2011.01.020]

[12] Shavitt S, Cho YI, Johnson TP, Jiang D, Holbrook A, Stavrakantonaki M. Culture moderates the relation between perceived stress, social support, and mental and physical health. J Cross Cult Psychol. 2016; 47(7):956-80. [DOI:10.1177/0022022116656132]

[13] Bahrainy H, Khosravi $\mathrm{H}$. [Comparative study of the impact of micro-climate features on urban behaviour patterns, the case of urban spaces of Yazd (warm and dry climate) and Fuman (moderate and humid climate) (Persian)]. J Environ Stud. 2015; 41(2):465-82. [DOI:10.22059/JES.2015.54994]

[14] Chappells H, Shove E. Comfort: A review of philosophies and paradigms [Internet]. 2004 [Updated 2004]. Available from: https://www.lancaster.ac.uk/fass/projects/futcom/ fc_litfinal1.pdf

[15] Nikolopoulou M, Steemers K. Thermal comfort and psychological adaptation as a guide for designing urban spaces. Energy Build. 2003; 35(1):95-101. [DOI:10.1016/S03787788(02)00084-1]

[16] American Society of Heating, Refrigerating and AirConditioning Engineer (ASHRAE). Thermal environmental conditions for human occupancy. New York: ASHRAE: 2010. http://arco-hvac.ir/wp-content/uploads/2015/11/ ASHRAE-55-2010.pdf

[17] Szúcs Á. Wind comfort in a public urban space-case study within Dublin Docklands. Front Archit Res. 2013; 2(1):50-66 [DOI:10.1016/j.foar.2012.12.002]

[18] Al-Kurdi N, Awadallah T. Role of street-level outdoor thermal comfort in minimizing urban heat island effect by using simulation program, Envi-Met: Case of Amman, Jordan. Res J Environ Earth Sci. 2015; 7(3):42-9. [DOI:10.19026/rjees.7.1694]

[19] Fallah Ghalhari GA, Mayvaneh F, Shakeri F. [Evaluation of thermal comfort and human health using Universal Thermal Climate Index (UTCI) case study: Kurdistan province (Persian)]. Iran J Health Environ. 2015; 8(3):367-78. https://ijhe. tums.ac.ir/article-1-5479-en.html

[20] Mas'oudi-nejad M, Tahbaz M, Mofidi Shemirani SM. [The study of the thermal performance of Shavadoons, case study: The Souzangar house in Dezful, Iran (Persian)]. J Iran Archit Stud. 2018; 7(13):49-70. [DOI:10.22052/1.13.49]

[21] Rijal HB, Humphreys M, Nicol F. Adaptive thermal comfort in Japanese houses during the summer season: Behav- 
ioral adaptation and the effect of humidity. Buildings. 2015; 5(3):1037-54. [DOI:10.3390/buildings5031037] 